\title{
An Analysis of Factors Affecting Depression among the Elderly in Penang, Malaysia
}

\author{
Rose Jacob*, Asmar Ahmad Bakhari, Munirah Ahmad \\ Faculty of Social Sciences, Social Work Program, University of Science, Malaysia
}

\begin{abstract}
Malaysia is experiencing "graying of the planet" and would fall into the category of Ageing Population in 2030. This is a phenomenon caused by an increase of elderly in a developing country. Although depression is the most common psychiatric disorder in the elderly, it is commonly not recognized, misdiagnosed and under treated as depression is perceived as part of normal ageing. The untreated depressive elderly have significant social implications as these disorders decreases an individual's quality of life and increases dependence on others. This paper reports the preliminary findings from a current research done in Penang. The Geriatric Depression Scale (GDS) is a 30 item self-report assessment used to identify depression among the elderly. The GDS questions are answered "Yes" or "No", instead of a five category response set. This simplicity enables the scale to be used with ill or moderately cognitively impaired individuals. Among the factors affecting depression among with the elderly is loneliness, chronic health issues and pain, impairment, loss of loved one/ones, tragic episode, lack of care givers, financial issues, suicide and the loss of interest in living. Elderly females were found to be almost three times more depressed compared to elderly men. These factors need to be addressed immediately for better social and physical functioning among the elderly.
\end{abstract}

Keywords Depression, Elderly, Impairment, Old Folks Home, Lonely, No Desire to Live

\section{Introduction}

Aging Population is a phenomenon when the population of the elderly comprises more than $15 \%$ of the country's population. According to United Nations Department of Economic and Social Affairs (UNDESA) in 2012, there would be $16 \%$ of the elderly in 2030 and an increase to $22 \%$ in 2050. In the World Assembly on Aging in Vienna in 1982, the United Nations has defined old age when a person is 60 years old and above. They are also referred to as the elderly or senior citizens. According to United Nations, the elderly in Malaysia will double from $7 \%$ to $14 \%$ in 28 years in 2030 . The world is experiencing dramatically increased numbers of people living to an advanced old age. Often referred to as "the graying of the planet," this dramatic increase represents the most significant population shift in recent history (Obaid \& Malloch-Brown, 2002).

Population aging refers to the increasing proportion of elderly within a population. The world population aging is a phenomenon caused by an increase in the absolute and relative number of elderly in developed and developing countries. This is a result of dramatic decline in mortality rates and increase in life expectancy over the last 50 years and also sharp falls in birth rates, especially in nearly all developing countries. In the year 2000, there were about 600 million elderly, aged 60 and over. Approximately two thirds of the world elderly are living in developing countries. There are currently more than 20 developing countries in which life expectancy at birth is 72 years and above, which also includes Malaysia (World Health Organization, 1998). In anticipation of this shift in population demographics, primary health care providers need to be alert and informed of the special needs of the elderly (Ebrahim, 1995).

\section{Depression}

Depression is an affective illness characterized by depressive symptoms such as disturbance in mood, cognition and behavior (Burke, Laramie, 2000). Although depression is the most common psychiatric disorder in the elderly, it is commonly misdiagnosed and under treated. The untreated depressed elderly patients have significant clinical and social implications as these disorders decreases an individual's quality of life and increases dependence on others (Blanchard, Mann, 1994). The manifestations of depressive disorders in the elderly are also different compared to other periods of adulthood. Doctors may have problems in eliciting history as a result of the presence of cognitive impairment in the elderly. Reluctance or denial by the patient and family members may also complicate the doctor's assessment (VanDerPol, Setter, Hunter, Pamintuan, 1998).

Depression is more than sadness. People with depression may experience a lack of interest and pleasure in daily activities, significant weight loss or gain, insomnia or excessive sleeping, lack of energy, inability to concentrate, feelings of worthlessness or excessive guilt and recurrent thoughts of death or suicide. Depression is the most common 
mental disorder. Fortunately, depression is treatable. A combination of therapy and antidepressant medication can help ensure recovery (Encyclopedia of Psychology, 2000). Depression is a common mental disorder that presents with depressed mood, loss of interest or pleasure, decreased energy, feelings of guilt or low self-worth, disturbed sleep or appetite, and poor concentration. Moreover, depression often comes with symptoms of anxiety. These problems can become chronic or recurrent and lead to substantial impairments in an individual's ability to take care of his or her everyday responsibilities. At its worst, depression can lead to suicide (World Health Organization, 2012).

Depressive illness is the commonest psychiatric disorder in old age, and has been reported to have a prevalence of 11 to $16 \%$ in the population over 65 years in the United Kingdom, and getting lower with increasing age. The prevalence is much lower than that for the younger age group although one would expect more depression in the elderly because of more losses e.g. loss of employment, bereavement, isolation, ill-health and so on. However, the onset of depression in the elderly is often preceded by severe life events for example bereavement, loss of income, moving house, physical illness and so on. A good quality of relationships with others and positive life events tend to improve the outcome for depression. Symptoms of depression are very common among the elderly who often complain of feeling sad and lonely and being isolated from others (Krishnaswamy, 1997).

In Malaysia, Kampung Bahru, Kuala Lumpur the elderly showed that $25 \%$ had diabetes, $16 \%$ had low levels of serum calcium, 24\% had low levels of serum albumin and $51 \%$ had low hemoglobin levels. The prevalence of psychiatric disorders in those above 65 is reported as $5 \%$ with dementia, $13 \%$ with depression ( $4 \%$ major depression)and $12 \%$ with anxiety states ( $7 \%$ phobic) (Lindesay, Briggs, Murphy, 1989). Social contacts also tend to decrease with the deaths of close friends and relatives while physical ill-health cuts down their outings and visits. Complaints of sleep disturbances are common as the elderly generally require less sleep and this can be worse with superimposed depression. Besides that loss of weight due to problems with dentition can occur again complicating loss of weight due to depression (Krishnaswamy, 1997).

In the elderly, according to Williams with the passage of time, deterioration tends to occur first with sociability, followed by breakdown in carrying out domestic tasks and finally in personal tasks. A medical practitioner must be aware that social problems can set in with the onset of an acute illness episode or injury which is often reversible with appropriate treatment. However, with chronic disease problems, which develop gradually, the changes that occur are not so readily reversible requiring social and other support interventions to complement the treatment of the disease (Williams, 1995).

The many health problems faced by the elderly could result in functional, psychological and social disabilities. Functional disabilities result in restricted activity days, work loss days (if working), bed disability days, social isolation, reduced vigorous physical exercise, drop in activity tolerance, weakened muscles, bone loss and, feeling of physical incompetence. Psychological disability can result in loss of confidence, exaggerated withdrawal from unusual activities, feeling of physical incompetence, depression, anxiety, hypochondriasis, sleep disturbances, suicidal tendencies. Social disabilities as a result of these chronic problems affect family relationships, worse in nuclear families and if the elderly is living alone in widowhood. Institutionalization for acute inter current problems or long term care can occur too (Berg, 1986).

Institutionalization is a risk that the elderly face. Institutionalized elderly often experience excess morbidity and mortality and this is aggravated if they are not the ones making the decision. The lack of adequate contact with family and friends and the tendency for excessive custodial attention can result in the institutionalized elderly being depressed and withdrawn. Financial or fiscal disability is a problem the elderly face when institutionalized. Considerable anxiety and grief result from worrying about the costs of their institutionalization, especially if they are using their personal resources (Berg, 1986).

\section{Methodology}

This research used a qualitative approach. A total of 20 respondents took part in this research, comprising respondents from an Old Folks Home and respondents from the community. A comparison between these two categories is presented at the end of the research. This paper reports the preliminary findings of the research done at an Old Folks Home in Penang comprising 7 respondents. The respondents comprise of Malay, Chinese and Indian representing the various races in Malaysia. The respondents aged above 60 years old, have either mild or severe depression, cognitively alert and willing to take part in this research.

The Geriatric Depression Scale (GDS) by Mark H. Ebell, 2001 was used to assess the level of depression among the respondents in this research. GDS is a 30 item self-report assessment used to identify depression in the elderly. The scale was first developed in 1982 by J.A. Yesavage and others. The GDS questions are answered "yes" or "no", instead of a five-category response set. This simplicity enables the scale to be used with ill or moderately cognitively impaired individuals. One (1) point is assigned to each answer and the cumulative score is rated on a scoring grid. The scale is commonly used as a routine part of a comprehensive geriatric assessment. It was found to have $92 \%$ sensitivity and $89 \%$ specificity when evaluated against diagnostic criteria. The Assessment is: $0-9=$ Normal, 10-19 = Mildly Depressed, 20-30 = Severely Depressed (Ebell, 2001).The GDS was validated against Hamilton Rating Scale for Depression (HRS-D) and the Zung Self-Rating Depression Scale (SDS).The data obtained regarding the level of depression of each respondent by using the GDS, Ebell, 2001) is as below: 
Table 1. Level of Depression using Geriatric Depression Scale by Ebell, 2001

\begin{tabular}{|c|c|c|c|c|c|c|c|}
\hline Category & Respondent 1 & Respondent 2 & $\begin{array}{c}\text { Respondent } \\
3\end{array}$ & Respondent 4 & Respondent 5 & Respondent 6 & Respondent 7 \\
\hline Age & 82 & 75 & 82 & 74 & 70 & 70 & 70 \\
\hline Sex & Male & Male & Female & Female & Female & Female & Male \\
\hline Marital status & Widower & Bachelor & Spinster & Widow & Spinster & Spinster & Bachelor \\
\hline Previous job & $\begin{array}{c}\text { Air force } \\
\text { Administration }\end{array}$ & Technician & Tailor & Housewife & Shop assistant & Shop assistant & Lecturer \\
\hline GDS Scale & Severe & Mild & Severe & Mild & Mild & Mild & Severe \\
\hline
\end{tabular}

\section{Findings}

\section{Profile of Respondents}

All seven respondents are above 70 years old, three males and four females and comprise of the Malay, Chinese and Indian race. One respondent is a widower, another is a widow, two bachelors and three spinsters. All the respondents were working prior to their placement in the Home except for one respondent who was a full time housewife. Three respondents were assessed as having severe depression while four respondents were mildly depressed. All the respondents hailed from Penang, Malaysia. They were all very cooperative in this research and always welcomed the researcher for her data collection.

\section{Reasons for Admittance to a Home}

All the respondents voiced out their frustrations that they had no choice but to be admitted to the Home. The main reason given is that the respondents did not have a caregiver to take care of their needs. Neither did they have a house to live in. The first respondent, a widower, became depressed after his wife died. Then after an accident his right limbs became weak. He had no children and all his siblings died. Having no caregiver, he decided to sell his house which was a difficult decision for him and admitted himself to the Home. His life was filled with bad memories and three sad happenings one after another which made him become more miserable. He worked in the administration of the Australian Air Force and had a comfortable life earlier. He is assessed with severe depression.

The second respondent who is a bachelor did not have a family or a house of his own. He only had one good friend whom he trusted. However, his friend left him in the Home and has never visited him since. He tried to contact this friend but there was no response from him. He felt cheated with this friend. He has worked as a technician with an average income. He is assessed with mild depression. The third respondent is a spinster. She neither has a house nor a family of her own. She has no caregiver and hardly any friends. She is restricted in her movements as she is wheel chair bound. This is the main reason for her placement in the Home. Previously she worked as a tailor with average earnings. She is assessed with severe depression. The prevalence of depression was more than tripled among the unmarried (widowed or single) compared to those who are married in the present study. We believe this is as a result of the lack of support and loneliness among the elderly who remain unmarried. Another study among the elderly in a rural community also found that the prevalence of depression was higher among the unmarried compared to those still married. Other studies have found that elderly who are married lead a better quality of life compared to elderly who are single, divorced or widowed. (Tan, 1992, Chia 1995).

The fourth respondent is a widow. Her step child sent her to the Home after her husband died. An elderly female also experiences loss of income and changes in living environment once they are widowed. In developing countries like Malaysia, the situation is even worse as most elderly women are financially dependent on their spouses and are from the lower socioeconomic group. (Sherina, 2003). Although she has three children of her own, they stay in Kuala Lumpur and hardly visit her. They also do not wish to take care of her. This respondent was a full time house wife and had no other job. However her grand-daughter visits her often at the Home. She needs help as she is unable to move around on her own. She is assessed with mild depression. The fifth respondent is a spinster whose younger sibling sent her to the Home. Her younger sister could no longer take care of her due to work commitments. She does not have a family nor a house of her own. She also needs help in her movements as she can only walk with the help of a walking frame. She is assessed as having mild depression.

The sixth respondent comes from a poor family. She has experienced poverty at a young age. After an accident which caused her to be immobile, her employer sent her to the Home. She needs total care as she is dependent on a caregiver. Thus being in a Home is the best option for her. She worked as a Shop Assistant with only an average income. She is assessed with mild depression. The seventh respondent worked as a lecturer in a local university. As a bachelor, he stayed with his elder sister who took care of him until he had a stroke. His elder sister sent him to the Home as she could no longer look after him. He is very upset and disappointed that his elder sister has never visited him in the Home. Having had a comfortable life with his high income, he finds it hard to cope in a Home. He is assessed with severe depression.

\section{Health and Impairment}

Three respondents have diabetes and four respondents have hypertension. Six respondents need to use assistive 
devices to help them to move due to their weak limbs. Four respondents use the wheel chair, one uses the walking frame while another uses a walking stick. One respondent suffers from Osteoperiostitis while another from stroke. One respondent has an iron plate in her leg and has very restricted movements. She depends on the nurse $100 \%$ for her daily needs. She also experiences severe pain in the affected leg when there is a bad thunderstorm or lightning. One respondent has sleep disturbances while another is always sleeping. The needs of six respondents have to be taken care who are dependent on the nurses while one respondent who is mobile is quite independent.

In Malaysia the elderly are generally less well off financially compared to the rest of the adult population as a result of their inability to earn. The elderly depend on their pension, savings, investments or even money from their children to meet their financial needs, which include seeking health care. (Arokiasamy, 1997). The elderly who were unemployed were also more depressed compared to those who were still employed. All these factors are commonly found in the lower socioeconomic groups of the community. Studies have found that among the lower socioeconomic groups, there is an increased rate of depression among the elderly. This is as a result of multi factorial elements such as inadequate diet, poor housing, poor health and medical care and the combination of family and community disorganization. (Lobo, 1995).

\section{Happiness Staying in the Home}

All the respondents are not happy at all staying in the Home. They have no friends in the Home. In my observation, most of the respondents lead withdrawn lifestyles. The Home is noisy and the respondents have no peace of mind. There are lots of arguments between the staff and residents and among the staff themselves. The staff have been rated as unfriendly by all the respondents. The respondents are unable to enjoy their meals as they are required to eat their meals fast due to the short duration of time given. One respondent explained further that the nurses are too strict and she does not like them nor likes staying in the Home. One respondent is forced to do physiotherapy which she is not comfortable with. Two respondents do not want to eat to their contentment for fear that the nurses would be angry if they need help to go to the toilet. There is hardly any privacy for the respondents as they are placed in an open dormitory. The unhappiness in the respondents has further aggravated the level of depression in them. It appears that their placement in the Home is followed by death.

\section{Desire to Live}

Six respondents do not wish to go on living. Two respondents said "I have lived long already". Another respondent said "I am counting the days. I had a satisfactory life and had enough. I have experienced everything in life for example travel and staying in big hotels. I have also been in prison. But I have not been a murderer or a rapist". Another respondent feels he is old already which is his justification to die. One respondent said he is very lonely as he does not have a family of his own. Nobody comes to visit him at the Home. Another respondent said "There is nothing to live for". His only wish is to die soon. Only one respondent hopes that she would be able to walk again. This respondent comes from a poor family and has experienced poverty from a young age. She had wanted to get married but could not as she was poor and had to take care of her parents then. Her level of depression is categorized as "mild". Surprisingly none of the other respondents mentioned about wanting to get better. Depression also occurred more frequently among the elderly who lived alone compared to those who lived with their family. This could also be as a result of social isolation which leads to the development of depression among the elderly. This finding is also similar to the recent study on depression among the elderly in a rural community in Malaysia (A. Mustaquim, unpubl. data, 2002).

\section{Coping Skills / Defense Mechanism}

One respondent said "I am having a normal life, no problems and no regrets. Do I look depressed?" This respondent is in denial and does not want to admit that he is depressed. He is always smartly dressed. His outward appearance does not show that he is depressed. This respondent is assessed as severely depressed. Another respondent whose friend had cheated him wants to look out for new friends whom he can trust. This respondent does not have any health issues and tries to think positive. Having a positive perspective has helped him to cope better. He is classified as having mild depression. To a question whether she had any regrets for not being married, one respondent answered "Being married or single is the same". She assures herself that she has not lost anything in life nor is depressed for being single. She also does not want to compare herself with others especially with the others who are married. The fourth respondent felt she had a contended life as she did good deeds to her husband and friends. According to her, she has always been "giving and caring". As such she feels that with her sacrifices, she will have a good life. She always thinks positive and wants to have a good heart towards others. Her grand-daughter visits her frequently at the Home. Her relationship with her grand-daughter has given her some family social support.

The fifth respondent overcomes her sadness by telling herself that at the Home there is somebody to give her food and take care of all her needs. For this she wants to be thankful. Otherwise she would not know how she would be able to survive. She does not want to have any negative feelings within her and wants to be positive at all times. Her thankfulness and gratefulness helps her to move on. However she sleeps most of the time. The sixth respondent watches television most of the time and keeps herself occupied with the programs and serial dramas. She is also thankful that there is somebody to provide for her needs and look after her at the Home. She does not think negatively about anybody and minds her own business.

The seventh respondent consoles himself that one day 
everybody will and must die. He has seen other inmates at the Home die often. As such he is quite immune to people dying. Although he is suffering from stroke and feels he has been let down by his elder sister for sending him to the Home, he wants to cope with this situation by telling himself that nobody can live forever. He reads books and novels to keep his mind occupied. He has some collection of novels in his cabinet at the Home. His liking for reading is probably due to the fact that he has worked as a lecturer prior to his ill health. He enjoys eating outside food and not the Home food. As he receives monthly pension, he gets somebody at the Home to buy especially Indian food from outside the Home. In this way he keeps himself quite happy and is able to enjoy some pleasures to a certain extent. From the questionnaire, this respondent is severely depressed.

\section{Conclusion}

One limitation of the present study is that the respondents are quite mobile and come from the same Old Folds Home. Respondents who are bed-ridden or cognitively unstable were not included in this research. Therefore although the present study reflects the prevalence of depression among the elderly, it does not represent the Malaysian population at large. However, from the findings of this research, the factors affecting depression among the elderly include lack of caregivers, health, impairment, sleep disturbances, finance, loneliness, dependence, basic needs, lack of desire to live, loss of spouse and lack of family support. When the elderly are not involved in the decision of being relocated from their home to an institution, this further aggravates the depression within them. The elderly who have lived comfortably during their younger days and now being institutionalized have a higher level of depression. The research also shows us that the elderly try to cope with their depression in various ways which includes defense mechanism. The recent developments regarding the elderly show clearly that there is an urgent concern for the physical and emotional needs of the elderly to be addressed quickly. Researchers have to be connected to the practical concerns of the elderly. Students need to be trained and exposed to working with the elderly. There must be an emphasis of community work through transferring of knowledge and skills involving the elderly. In the final analysis it is about understanding the elderly and to help them cope with their depression. This would indeed help them to age gracefully and face death with dignity.

\section{Acknowledgements}

The authors would like to especially thank Universiti Sains Malaysia for giving us a grant to conduct and support this research without which this research could not be conducted. We are indeed indebted to the staff of the Old Folks Home who assisted in this research and to all the respondents whose cooperation and participation helped make this research possible.

\section{REFERENCES}

Arokiasamy J.T. (1999). Malaysia's Ageing Population: Challenges in the New Millennium. Med J Malaysia Vol 54 N0 4 Dec 1999.

Berg R. L. The prevalence of disability in the aged. In: Last JM (ed) Maxcy-Rosenau Public Health and Preventive Medicine, Twelfth Edition, Appleton-Century-Crofts, Norwalk, Connecticut, 1986.

Blanchard MR, Waterraus A, Mann AH. The nature of depression among older people in inner London and the contact with primary care. Brit. J. Psych. 1994; 164: 396-402.

Burke MM, Laramie JA. Primary Care of the Older Adult, $1^{\text {st }}$ edn. St Louis: Mosby, 2000.

Catherine N. Dulmus, James A. Blackburn. 2007. Handbook of gerontology, evidence based approaches to theory, practice and policy. John Wiley \& Sons, Inc., Hoboken, New Jersey.

Chia YC. Primary Care in the Elderly. In: Srinivas P (ed). Proceedings of the First National Symposium on Gerontology 1995. Kuala Lumpur: University Malaya, 1995.

Ebrahim S. Public Health Implications of Ageing. In:Srinivas P (eds). Proceedings of the First National Symposium on Gerontology 1995. Kuala Lumpur: University Malaya, 1995; 6-20.

Karim H.A. (1997). The Elderly in Malaysia. Med J Malaysia Vol 52 No 3 Sept 1997.

Krishnaswamy S. (1997). The Elderly in Malaysia. Med J Malaysia Vol 52 No 3 Sept 1997.

Lindesay, Briggs K, Murphy E. The Guy's Age Concern Survey. Prevalence Rates of Cognitive Impairment, Depression and Anxiety in an Urban Elderly Community. Brit J Psy1989; 155: 317-29.

Lobo A, Saz P, Marcos G, Dia JL, De-La-Camara C. The prevalence of dementia and depression in the elderly community in a southern European population. Arch.Gen. Psych. 1995; 52: 497506.

Mark H. Ebell. 2001. Evidence based diagnosis. A handbook of Clinical Prediction Rules.

Obaid, T. A., \& Malloch-Brown, M. (2002). Joint statement to the Second World Assembly on Ageing. April 8-12, 2002, Madrid, Spain.

Sherina Mohd. Sidik (2003). Factors Associated with Depression among Elderly Patients in a Primary Health Care Clinic in Malaysia. Asia Pacific Family Medicine 2003; 2:148-152

Sowers, K. M., \& Rowe, W. S. (2006). Social work and social justice: From local to global perspectives. Belmont, CA: Thomson Learning.

Tan PC. Ageing in Caring Society - The Implication of Changing the Family Structure in Malaysia. Seminar of Counselling and the Family in Conjunction with 'Expo the Caring Face Technology' UTM, Johor Bahru, 18-19 December 1992. 
UKM 29/94. Project report: A Study on the elderly in Kampung Bahru, Kuala Lumpur 1994.

VanDerPol CA, Setter SM, Hunter KA, Pamintuan H. Depression in community dwelling elders. Postgrad. Med.1998; 103: 165-7. 9 Schwenk TL, Coyne JC, Fechner-Bates S. Differences

Wiles, J (2005). Conceptualizing place in the care of older people: the contributions of geographical gerontology. International Journal of Older People Nursing in Association with Journal of Clinical Nursing.

Williams E. I. Care of older people in the community. In: Srinivas P, Poi PJH, Chia YC (eds). Proceedings of the first national symposium on Gerontology 1995 - Issues and challenges of ageing, Faculty of Medicine, University of Malaya,1996 : 21-29. 